\title{
Un educador comprometido con la transformación de la educación
}

An educator committed to the transformation of education

Um educador comprometido com a transformação da educação

\author{
Estela Socías Muñoz \\ Universidad Mayor (Chile) \\ https://orcid.org/0000-0003-0228-3430 \\ estelafrancisca.socias@gmail.com
}

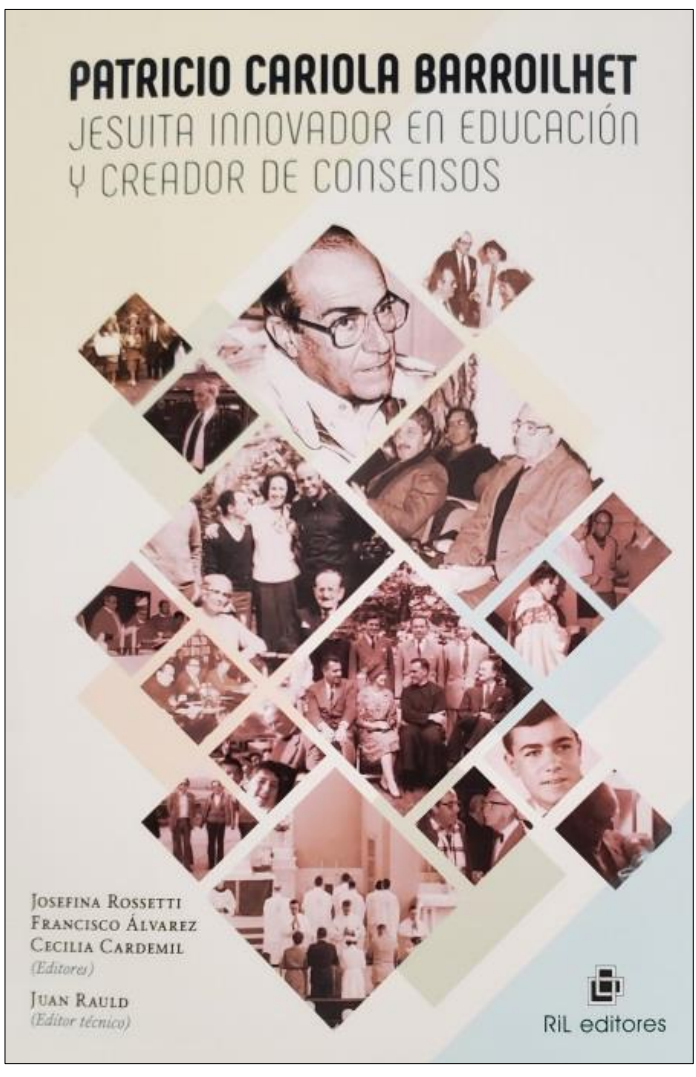

ROSSETTI，Josefina; ÁlVAREZ, Francisco; CARDEMIL, Cecilia (Editores). Patricio Cariola Barroilhet: Jesuíta Innovador en Educación y Creador de Consensos. Santiago de Chile: RIL Editores. 2019. 228p.

Autores: Francisco Álvarez Martín, Jaime Caiceo Escudero, Cecilia Cardemil Oliva, Leonor Cariola Huerta, Josefina Rossetti Gallardo, Rosa Saavedra Díaz \& Pablo Andrés Toro Blanco. 
El texto en comento es una obra que ha surgido por la unión de dos esfuerzos académicos: (i) La investigación sobre la vida y obra del sacerdote jesuita -Premio Nacional de Educación 1999-, iniciada hace algunos años por el Dr. Jaime Caiceo Escudero quien "ha escrito sobre todos los Premios Nacionales de Educación y recibió del propio padre Patricio, poco antes de su muerte, el encargo de escribir su biografía; ya en 2005 había plasmado una investigación científica sobre la vida y la obra del jesuita" (ROSSETTI ET AL., 2019, contratapa). (ii) Un grupo de académicos que trabajaron con el fundador del Centro de Investigación y Desarrollo de la Educación CIDE- en la misma institución en diversas labores de investigación y publicación; ellos son Francisco Álvarez Martín, Cecilia Cardemil Oliva, Leonor Cariola Huerta, Josefina Rossetti Gallardo, Rosa Saavedra Díaz, quienes deseaban dejar por escrito el significado y la importancia en favor de la educación por el sacerdote de la Compañía de Jesús, "un innovador en la educación chilena" (IBIDEM). Ellos, a su vez, invitaron al académico de la Universidad Alberto Hurtado, Pablo Andrés Toro Blanco, a fin de que escribiera el "marco sociocultural y político de la época en que vivió el padre Patricio" (IBIDEM).

Esta obra consta tres capítulos. El primero, denominado "El Chile que le tocó vivir", escrito por el Dr. Toro, quien describe y analiza con bastante propiedad histórico-culturaleducacional el período que abarca 73 años del acontecer chileno (1928-2001) en 22 páginas; una síntesis de sus reflexiones apuntan a que "Cariola acompañó con su trayecto vital el tránsito desde un Estado que buscó garantizar la educación como un derecho y como un insumo central para la transformación de la sociedad, de acuerdo a proyectos colectivos de profundas raíces históricas y utópicos propósitos (el desarrollo, el socialismo), hacia una revolución capitalista que frustró esos proyectos para depositar la soberanía de las decisiones educacionales en el mercado" (IBID, pp. 33-34).

El capítulo 2, "Vida y obra", en 68 páginas presenta en cinco puntos la biografía y la acción educativa de este insigne sacerdote jesuita: su vida familiar, su vida sacerdotal, la su labor en la FIDE, el CIDE y en la formación de REDUC y la semblanza de su personalidad. Patricio nació el 11 de junio de 1928, hijo de una familia de nivel socioeconómico alto; su padre se dedicó a la construcción como empresario; tuvo tres hermanos más. Desde pequeño, su padre le inculcó que iba a darle la mejor educación; de hecho, estudió en The Grange School, uno de los mejores colegios de la época de Santiago; su orientación era protestante. Sin embargo, con espíritu abierto, el establecimiento recibía visitas de católicos; fue así como fue motivado por unos discípulos del P. Alberto Hurtado, a conocerlo y así conoció al santo chileno -canonizado el 23 de octubre de 2005 por Benedicto XVI-, quien lo cautivó y lo motivó a ingresar a la Compañía de Jesús. Inició su formación religiosa en Chile, pero los estudios filosóficos y teológicos los realizó en Argentina y Bruselas. Su ejercicio sacerdotal estuvo ligado a la labor educativa en colegios y en parroquias de sectores populares, Cerro Navia (Santiago) y La Chimba (Antofagasta); su compromiso con los pobres y perseguidos le significó participar en el Comité Pro Paz -creado por las iglesias católica, evangélicas y judía durante el inicio de la dictadura militar- y ser detenido por la policía secreta del régimen por dos meses. En síntesis, "Patricio Cariola fue un gran servidor de la Iglesia Católica, marcando a la gente con su temple, con su espíritu cálido y con su humildad” (IBID, p. 54). Al jesuita le tocó vivir los tres proyectos políticos excluyentes que hubo entre 1958 y 1973, uno de derecha clásica con Jorge 
Alessandri, otro socialcristiano con Eduardo Frei Montalva y uno de izquierda con Salvador Allende, interrumpido con el golpe militar de 1973. En 1964 ingresó a la Federación de Institutos de Educación -FIDE- en donde llegó a ser el Presidente. Desde allí respaldó al reforma educacional de Frei de 1965, inspirada en el humanismo cristiano y en la pedagogía de los discípulos de Dewey, Tyler y Bloom; en el gobierno de Allende tuvo que defender la educación particular, puesta en peligro por algunos representantes de ese gobierno, aunque el propio presidente detuvo la implementación de la Escuela Nacional Unificada -ENU- impulsada por el gobierno y dejada de lado por petición del Cardenal Raúl Silva Henríquez. En la FIDE, Cariola había fundado un Centro de Investigación Educacional, el cual, al dejar la institución, surgió como institución independiente con el nombre de CIDE. Durante la dictadura militar logró financiamiento de la Fundación Ford, gracias a lo cual envió a investigadores jóvenes a doctorarse a "universidades extranjeras, como Lovaina, Massachusetts, Harvard y California" (IBID, p. 68). Al regresar los nuevos doctores en educación comenzaron a realizar diversas investigaciones sobre la educación chilena y cómo resolver sus profundos problemas de desigualdad cuando volviera la democracia; en todo ello, el P. Cariola era el cerebro organizador y buscador de recursos, transformando al CIDE en el mejor centro de investigación educacional en las tres últimas décadas del siglo pasado. Para proyectar los trabajos investigativos funda una sección de la Revista Latinoamericana de Estudios Educativos REDUC-, creada en México; la sección, aún existente son los Resúmenes Analíticos en Educación -RAE-, que sintetizan las investigaciones de varios países latinoamericanos. La semblanza de la personalidad del P. Patricio se expresa en su gran capacidad de contacto y acogida, su sentido social, en ser un formador, un visionario y promotor de redes.

"El liderazgo y la vigencia de Patricio Cariola" es el título del capítulo 3. Está dividido en 5 partes: (i) "El sacerdote jesuita" elaborado por Josefina Rossetti en 34 páginas en donde resalta la matriz jesuita en la práctica de los Ejercicios Espirituales de San Ignacio de Loyola; el trabajar siempre en las fronteras geográficas o culturales; el dedicar su vida a una congregación educadora; con una gran capacidad de emprendimiento para pedir para otros, pero con dependencia personal de su Compañía y su voto de pobreza; su manera de ser estaba imbuida de los valores cristianos (flexible, generoso, solidario, escuchador de los problemas de los otros, apoyador); se sentía que pertenecía y confiaba en la Iglesia Católica; su forma sobria para impartir los sacramentos; su fe expresada en la acción; su compromiso pastoral y su preocupación por su comunidad. (ii) "Derechos humanos, solidaridad, recuperación de la palabra", abordado por Rosa Saavedra en 20 páginas, en donde subraya no solo la defensa de los derechos humanos y la solidaridad en escritos e intervenciones públicas sino que en la práctica en el Comité Pro Paz, primeramente sino que luego en la Vicaría de la Solidaridad creada por el Cardenal Arzobispo de Santiago, Raúl Silva Henríquez; en esas instituciones el P. Patricio protegió, ayudó, recibió en el CIDE con trabajo y logró que fueran acogidos en otros países a muchos perseguidos por la dictadura militar imperante, sin hacer distingos sociales, políticos o religiosos; de esta forma, logró que los que lograron permanecer en su patria, recuperaran su palabra. (iii) "La fisonomía de un educador esencial" es elaborado por Francisco Álvarez y Cecilia Cardemil en 21 páginas, señalando una serie de características de un buen educador, las cuales estaban presentes en el sacerdote jesuita: 
entusiasmo por enseñar, manifestando energía y vitalidad; enseñar a aprender a pensar por sí mismo; incentivar el despliegue de nuevos horizontes; promover la autonomía en el proceso de aprendizaje; asumir los cambios, proyectarlos y crear otros; anticipar necesidades y emprender formas creativas de atenderlas, como REDUC, por ejemplo; capacidad para mejorar e innovar las condiciones de vida y de trabajo de quienes se forman; combinar distintos tipos de trabajo y agrupamiento de los participantes, fomentando el trabajo colaborativo e individual; capacidad de visión integral de la sociedad y de ser un auténtico agente de cambios; construir relaciones profesionales y de equipo con sus colegas, ej: Talleres metodológicos para profesores. (iv) "Vigencia del pensamiento y liderazgo en investigación educacional”, escrito por Leonor Cariola en 8 páginas; señala que es una de las personas que más impulsó en la segunda mitad del siglo pasado la investigación educacional desde la institución que él mismo creara -Centro de Investigación y Desarrollo de la Educación; para él, la investigación debía tener un fundamento epistemológico, pero la orientaba especialmente a la investigación-acción; él mismo practicaba los focus groups. (v) "Su pensamiento educativo", elaborado por Jaime Caiceo en 20 páginas; a partir de las conclusiones del Concilio Vaticano II, el P. Patricio afirma, siguiendo a su mentor religioso, San Alberto Hurtado, que la educación tiene un sentido social y que la escuela católica debe promover el diálogo entre la Iglesia y la sociedad; defiende la educación particular, llegada al país con las primeras congregaciones religiosas durante la colonia, pero asumiendo la Conferencia de la Conferencia Episcopal Latinoamericana -CELAM- de 1968, plantea la integración social y la educación liberadora, el concepto de comunidad escolar, impulsa la educación popular, la educación para el trabajo, la educación para todos -por lo mismo participó a nombre del país en el Primer Encuentro Mundial con tal objetivo en Jomtiem en 1990 -; lleva a la práctica la estrecha relación que debe existir entre educación e investigación; el Dr. Caiceo termina señalando "que el P. Hurtado y el P. Cariola son, sin lugar a dudas, los principales exponentes del sector católico que más han influido en el sistema educativo chileno durante el siglo XX. No hay que olvidar que, hasta la Reforma Educacional de 1965, los planteamientos educacionales para el país fueron realizados por grandes educadores, pero del sector laicista” (IBID, p. 205).

Como se puede apreciar, este libro en comento presenta a un gran educador que influyó no solo en Chile sino que en Latinoamérica a través de REDUC; es un digno hijo de San Ignacio de Loyola que supo combinar su vida religiosa con el servicio a los demás desde uno de los pilares evangélicos, "Id y enseñad a todas las gentes" (Mateo, 18, 19). 